\title{
Diapause development in Aquarius paludum (Heteroptera: Gerridae)
}

\author{
Tetsuo HARADA ${ }^{1}, \mathrm{Ken}_{\mathrm{ITO}}{ }^{1}$, Magdalena HODKOVA² $^{2}$ and Ivo HODEK ${ }^{2}$ \\ ${ }^{1}$ Laboratory of Environmental Physiology, Faculty of Education, Kochi University, Kochi 780, Japan; \\ e-mail: haratets@cc.kochi-u.ac.jp \\ ${ }^{2}$ Institute of Entomology, Academy of Sciences, 37500 Ceske Budejovice, Czech Republic; e-mail: hodkova@entu.cas.cz
}

Key words. Aquarius paludum, Gerridae, water striders, diapause induction, diapause development, reactivation, oxygen uptake, ovarian maturation

\begin{abstract}
Diapause fixation and development were studied in females of a Czech population of Aquarius paludum by monitoring changes in oxygen uptake, weight and reproduction potential in field adults between August and February. The fall in oxygen uptake related to fresh weight (from $>1000 \mu 1 \mathrm{O}_{2}$ per g per h to around $500 \mu 1 \mathrm{O}_{2}$ per g per h) in field adults during early diapause was similar in two age cohorts, although the time of adult ecdysis differed by 50 days and thus occurred at markedly different temperatures and photoperiods of late August vs. early October. The different conditions affected the weight of females and thus also the absolute value of oxygen consumption: both parameters were much lower in the October females. The seasonal time of diapause termination in A. paludum did not differ from findings in other cold temperate insects: diapause and the photoperiodic response ended in the winter, as was shown by the possibility of insects' reactivation by $26^{\circ} \mathrm{C}$ in spite of a diapause promoting daylength of $12 \mathrm{~L}$ : 12D. In most females (78.6\%) ovaries matured after transfer to these conditions in mid-February, while ovarian maturation occurred in only $16.7 \%$ of females transferred in early January and no ovarian maturation was observed in females transferred in early December. Ovarian maturation was preceded by a transient increase in oxygen consumption from $600 \mu \mathrm{O}_{2}$ per g per h to $1400 \mu \mathrm{l}$ $\mathrm{O}_{2}$ per g per h.
\end{abstract}

\section{INTRODUCTION}

Although life-history adaptations and diapause induction under various environmental conditions were studied in several water strider species of the genus Aquarius (Heteroptera: Gerridae) (Blanckenhorn, 1994; Blanckenhorn \& Fairbairn, 1995; Harada, 1994, 1998; Inoue \& Harada, 1997; Harada et al., 2000; Harada \& Spence, 2000), the condition of the bugs in the course of diapause development and its termination remained relatively neglected, except for A. paludum. Gradual increase in daylength after winter solstice within the range of short days promoting diapause accelerated diapause development: strong positive phototaxis appeared early in diapause adults of A. paludum under long days, when they had previously experienced the increase in photophase within short-day photoperiods. The positive phototaxis appeared 2 weeks earlier than when they were kept only under constant short days before the transfer to long days (Harada, 1991). In the Kochi $\left(33^{\circ} \mathrm{N}\right)$ population of Gerris gracilicornis which is univoltine and adopts obligatory diapause, both short days in fall and the subsequent winter chilling were needed to end the very long diapause lasting more than 7 months (Harada \& Taniguchi, 2001). In other Gerridae the evidence on the physiological parameters of insects in diapause is very poor. The course of diapause termination (Hodek, $1971,1979,1983$ ) and changes in oxygen consumption (Hodek \& Hodkova, 1981) were, however, studied in detail in some terrestrial bugs, e.g. in Pyrrhocoris apterus (Pyrrhocoridae) or Aelia acuminata (Pentatomidae). The aim of this preliminary study was to check the eventual differences between aquatic and terrestrial heteropterans, particularly to establish the time of diapause termination.

\section{MATERIAL AND METHODS}

\section{Insects}

Adults and last instar larvae of Aquarius paludum (Heteroptera: Gerridae) were collected in ponds of south Bohemia (near to Ceske Budejovice, $49^{\circ} \mathrm{N}$ ) during late August and September of 2000. Insects were reared outdoors in containers with water and floating pieces of polystyren until December. Adult females aged 3-4 months were subsequently transferred to either $26 \pm$ $1{ }^{\circ} \mathrm{C}$ and short-day photoperiod (12L : 12D) on 7 December or 5 $\pm 2^{\circ} \mathrm{C}$ and continuous darkness in containers with moist moss on 26 December. We believed that the latter conditions adequately substituted for hibernation shelters which have not yet been found in nature. Females were stored under the latter conditions until 8 January or 12 February when they were transferred to 26 $\pm 1^{\circ} \mathrm{C}$ and short-day photoperiod (12L : 12D). Oxygen consumption was measured every $2^{\text {nd }}$ or $3^{\text {rd }}$ day after the transfer of females to $26^{\circ} \mathrm{C}$. At the end of each experiment, females were dissected under Ringer saline for insects and the state of ovaries was monitored. The state of testes is not a suitable indication of the progress of diapause development. Changes in oxygen consumption during 2-3 months after adult ecdysis were measured in early (ecdysis on 20 August) and late (ecdysis on 5 October) females kept continuously outdoors. Outdoor temperatures are given in Fig. 3. Insects kept outdoors or at $26^{\circ} \mathrm{C}$ were fed with frozen adult flies (Sarcophaga bullata).

\section{Oxygen consumption}

The metabolic rate was measured as oxygen consumption manometrically with a Warburg respirometer at $26^{\circ} \mathrm{C}$ (Slama, 1960). Respiratory vessels of about $10 \mathrm{ml}$ volume were employed with $5 \%$ potassium hydroxide to absorb carbon dioxide and with a small piece of wet cotton to maintain constant pressure of water vapor. The recorded value of oxygen consumption of each individual at rest represented an average from three $0.5 \mathrm{~h}$ readings. Females were weighed using an analytical balance (Sartorius) with the accuracy of $0.1 \mathrm{mg}$.

\section{Statistics}

Means \pm SEM are given in Figures and in the text. Difference between means was evaluated by Student's T-test. 

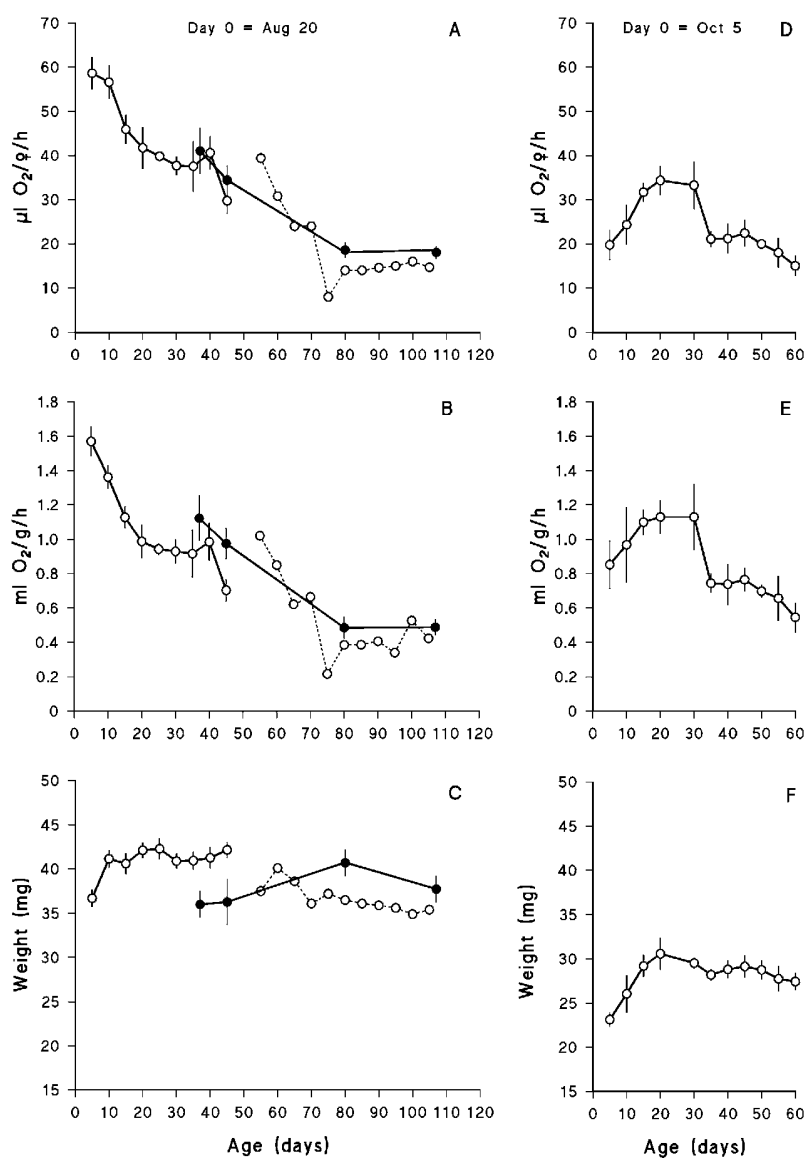

Fig. 1. Changes in oxygen consumption and fresh weight in two age cohorts of $A$. paludum females under field conditions. Day $0=$ the day of adult ecdysis. Open circles, means \pm SEM for every five days (full line, $\mathrm{N}=5$ for August females, $\mathrm{N}=3$ for October females, dotted line, $\mathrm{N}=1$ ). Closed circles, means \pm SEM for females measured at corresponding dates but the age is not precisely defined $(\mathrm{N}=10)$.

\section{RESULTS}

\section{Oxygen consumption in the field}

The adults that ecdysed in late August differed substantially from those ecdysed in early October, both in absolute oxygen consumption and weight. The freshly ecdysed August bugs consumed around $60 \mu 1 \mathrm{O}_{2}$ per female per $\mathrm{h}$, while the October individuals only about $20 \mu 1 \mathrm{O}_{2}$ (Fig. 1A, D). The average for the first 50 days of adult age was $42.6 \pm 1.8 \mu \mathrm{O}_{2}$ for the August females and $24.5 \pm 1.7 \mu \mathrm{O} \mathrm{O}_{2}$ for October females $(\mathrm{P}<<0.0001)$. When the oxygen consumption is related to the fresh weight, the difference becomes smaller (Fig. 1B, E), because also the weight differed much between the two samples (Fig. 1C, F). The August females consumed $1043.5 \pm 47.2 \mu 1 \mathrm{O}_{2}$ per g per $\mathrm{h}$, while the October females $890.4 \pm 60.7 \mu 1 \mathrm{O}_{2}$ per g per $\mathrm{h}(\mathrm{P}<$ $0.05)$. In both cohorts the oxygen consumption gradually decreased to the level of around $500 \mu 1 \mathrm{O}_{2}$ per $\mathrm{g}$ per h in females aged $>50$ days (Fig. 1B, E). The starting weight of August females was about $35 \mathrm{mg}$ and it was only about $23 \mathrm{mg}$ in October females. In both cohorts the weight increased during the first 10-20 days of life, so that the average value for the first 50 days was $40.9 \pm 0.4 \mathrm{mg}$ and $27.6 \pm 0.6 \mathrm{mg}$ in August and October, respectively $(\mathrm{P}<<0.0001)$.
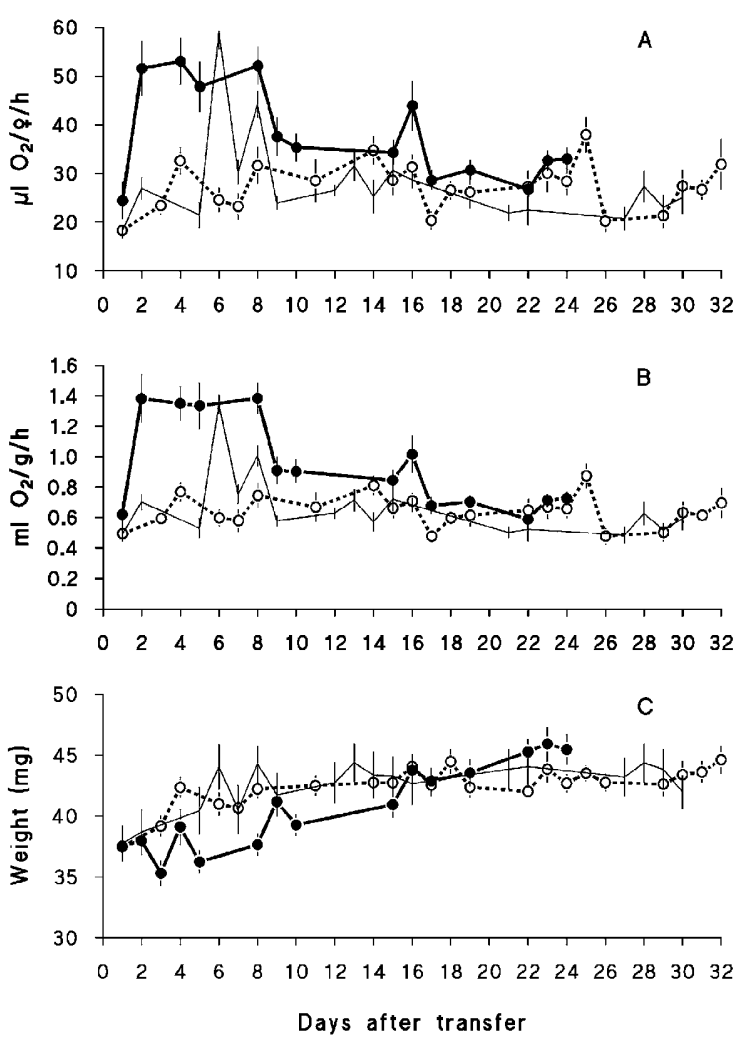

Fig. 2. Changes in oxygen consumption and fresh weight in A. paludum females transferred to $26 \pm 1{ }^{\circ} \mathrm{C}$ and $12 \mathrm{~L}: 12 \mathrm{D}$. Day $1=$ the day of transfer to $26 \pm 1^{\circ} \mathrm{C}$ from field conditions on 7 December (thin line, $\mathrm{N}=10$ ), from $5 \pm 2^{\circ} \mathrm{C}$ on 8 January (open circles, $\mathrm{N}=12-15$ ) or 12 February (closed circles, $\mathrm{N}=14-15$ ). Two last samples were transferred from the field to $5 \pm 2^{\circ} \mathrm{C}$ on 26 December. Means \pm SEM are given. Difference between means of oxygen consumption (A, B, days 2-8) for January and February samples is significant ( $\mathrm{P}<<0.0001)$ (Student's T-test).

\section{Transfers to laboratory}

The changes in diapause intensity during diapause development were estimated by incubations of three winter samples in a high temperature of $26 \pm 1{ }^{\circ} \mathrm{C}$ and a diapause promoting photoperiod of $12 \mathrm{~L}: 12 \mathrm{D}$. One sample was directly transferred from outdoor to incubation conditions on 7 December. Two samples from 26 December were first exposed to $5 \pm 2{ }^{\circ} \mathrm{C}$ for 2 and 6 weeks, so that they were transferred to incubation conditions on 8 January and 12 February, respectively. An important progress in diapause development evidently occurred between the last two dates, as was shown both by changes in oxygen consumption and weight during a 4 week incubation and by the state of ovaries after a 4 week incubation. The oxygen consumption in the January females remained near the level of 500-700 $\mu 1 \mathrm{O}_{2}$ per g per h (18-35 $\mu 1 \mathrm{O}_{2}$ per female per $\left.\mathrm{h}\right)$ during the one month experiment, while the oxygen consumption in the February females sharply increased within one day to $1400 \mu \mathrm{l} \mathrm{O}$ per $\mathrm{g}$ per $\mathrm{h}\left(50 \mu \mathrm{l} \mathrm{O}_{2}\right.$ per female per $\left.\mathrm{h}\right)$ and was maintained at this level for at least one week (Fig. 2A, B). The weight of February females was lower during the first week but gradually increased during the next 3 weeks of incubation to about $47 \mathrm{mg}$. The weight of January females remained at a similar level during the 4 week incubation (Fig. 2C). Much higher incidence of females with matured eggs was recorded in February females $(78.6 \%, \mathrm{~N}$ $=14)$ than in January females $(16.7 \%, \mathrm{~N}=12)$. Ovaries of all December females $(\mathrm{N}=10)$ remained in pre-vitellogenic state. 


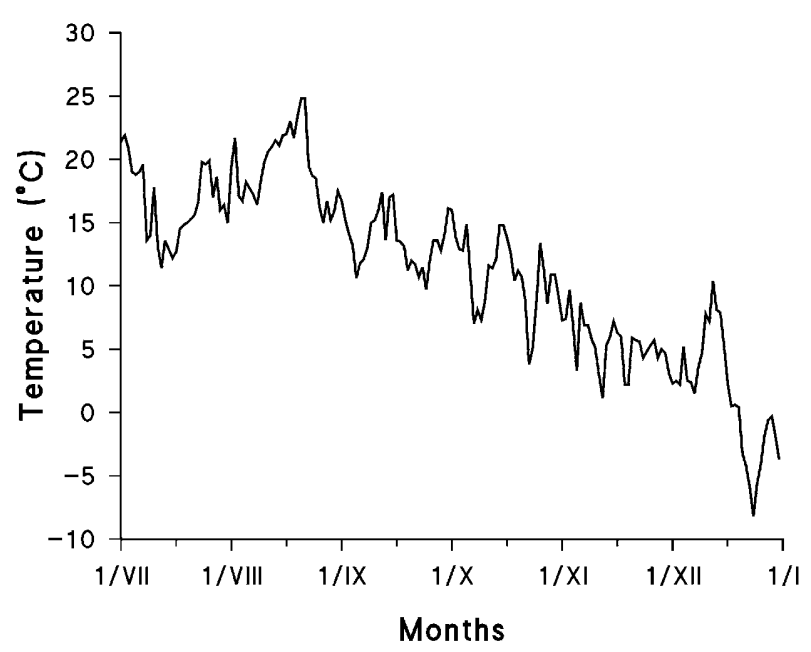

Fig. 3. Daily averages of field temperatures during the relevant period.

\section{DISCUSSION}

\section{Physiological conditions of field bugs}

The oxygen consumption per fresh weight is related to the age of adult females rather than to the date of sampling and outdoor conditions. This is shown by comparison of two age cohorts of females of A. paludum on the same date. On 10 October, the early ecdysed August females were 50 days old, while the late ecdysed October females were only 5 days old. While the oxygen consumption on that date already decreased to the values around $700 \mu 1 \mathrm{O}_{2}$ per g per $\mathrm{h}$ in the August females due to diapause induction (Fig. 1B), the oxygen consumption in the young October females was increasing (Fig. 1E). In spite of changed environmental conditions (daylength decreased by about $2 \mathrm{~h}$ and the average daily temperature by about $6^{\circ} \mathrm{C}$, Fig. 3 ), October females aged 15 days consumed more than $1000 \mu \mathrm{l}$ $\mathrm{O}_{2}$ per $\mathrm{g}$ per $\mathrm{h}$ and thus showed similar metabolic levels as the young August females aged 15 days (Fig. 1B, E). During the pre-diapause, the young bugs have to feed to accumulate energetic reserves in order to survive the starvation of the long hibernation period. At the age of 50 days both groups of females had similar oxygen consumption of around $700 \mu \mathrm{l}_{2}$ per g per h. Oxygen consumption further decreased to the level of around $500 \mu 1 \mathrm{O}_{2}$ per g per h, evidently typical for diapause. This value is similar to the values found in diapausing terrestrial bugs: in Dolycoris baccarum $480 \mu \mathrm{O}_{2}$ per g per h (Conradi-Larsen \& Sømme, 1978) and in Pyrrhocoris apterus $500 \mu \mathrm{l} \mathrm{O}_{2}$ per g per h (Hodek \& Hodkova, 1981). Also, similar, but double values were ascertained for active females in both terrestrial and aquatic bugs.

\section{Progress of diapause development}

Diapause intensity in A. paludum, indicated by several characteristics after the transfer from outdoors or $5 \pm 2{ }^{\circ} \mathrm{C}$ to $26 \pm$ $2^{\circ} \mathrm{C}$ and $12 \mathrm{~L}: 12 \mathrm{D}$, did not decrease substantially between early December and early January, but it did before early February. This was indicated by the ability of February females to increase abruptly the oxygen consumption after the transfer (Fig. 2B). The increased food consumption led to the increase in weight (Fig. 2C) and a resumption of ovarian maturation in $78.6 \%$ of females, in spite of exposure to diapause promoting short daylength. The fall in oxygen consumption after about one week incubation at $26^{\circ} \mathrm{C}$ might be due to temperature compensation of metabolism which is well documented in ectothermic organisms (Precht et al., 1973). Alternatively, the metabolic cost of the transition from non-reproductive to reproductive state may be higher than the maintenance of reproduction. The time of diapause termination in A. paludum does not differ from the general picture for adult diapause in insects in the cold moderate climate (Tauber et al., 1986; Danks, 1987). Similar time of diapause end was found in a terrestrial heteropteran, P. apterus (Hodek, 1971).

\section{Geographical difference in the role of temperature on termi-} nation of diapause

Diapause of the Kochi population in relatively weak. It was terminated quite easily by transfer to high temperature of $25^{\circ} \mathrm{C}$, irrespective of the previous duration of diapause induced in larvae by short day photoperiod $\left(12 \mathrm{~L}: 12 \mathrm{D}, 20^{\circ} \mathrm{C}\right.$ ) (Harada \& Taneda, 1989). In the population from Ceske Budejovice $\left(49^{\circ} \mathrm{N}\right)$, in the middle of diapause, i.e. in December or January, diapause was not terminated by transfer to $26^{\circ} \mathrm{C}$. Their diapause was induced in field conditions and the bugs were then kept at $5^{\circ} \mathrm{C}$ before transfer. It cannot be excluded that the difference between Japanese and Czech populations was partly caused by different diapause inducing conditions.

ACKNOWLEDGEMENTS. The study was supported by the Grant Agency of the Czech Republic (Grant 206/02/0900), by the grant for Japanese-Czech cooperation of the Czech Ministry of Education (ME 169/1998-2002) and from the Entomology Institute projects Z5007907 and 61/5113 (Acad. Sci. CR), and by Grants from The Japanese Ministry of Education, Science, Culture and Sports (Grant No. 10740361/1998-2000; Grant No. 11794001/ 1999-2002) and The Dan Charitable Trust Fund for Research in the Biological Sciences (1998).

\section{REFERENCES}

BlanCKENHORN W.U. 1994: Fitness consequences of alternative life-histories in water-striders, Aquarius remigis (Heteroptera, Gerridae). Oecologia 97: 354-365.

BlanCKENHORN W.U. \& FAIRBAirn D.J. 1995: Life-history adaptation along latitudinal cline in the water-strider Aquarius remigis (Heteroptera, Gerridae). J. Evol. Biol. 8: 21-41.

Conradi-Larsen E.-M. \& Sømme L. 1978: The effect of photoperiod and temperature on imaginal diapause in Dolycoris baccarum from southern Norway. J. Insect Physiol. 24: 243-249.

DANKs H.V. 1987: Insect Dormancy: an Ecological Perspective. Biological Survey of Canada, Ottawa, $439 \mathrm{pp}$.

HARADA T. 1991: Effects of photoperiod and temperature on phototaxis in a water strider, Gerris paludum insularis (Motschulsky). J. Insect Physiol. 37: 27-34.

Harada T. 1994: Adult diapause induced by the loss of water surface in the water-strider, Aquarius paludum (Fabricius). Zool. Sci. 11: 855-857.

HARADA T. 1998: To fly or not to fly: response of water striders to drying out of habitat. Ecol. Entomol. 23: 370-376.

Harada T. \& Spence J.R. 2000: Nymphal density and life histories of two water striders (Hemiptera: Gerridae). Can. Entomol. 132: 353-363.

Harada T. \& TANEDA K. 1989: Seasonal changes in alary dimorphism of a water strider, Gerris paludum insularis (Motschulsky). J. Insect Physiol. 35: 919-924.

Harada T. \& TANiguchi Y. 2001: Adult diapause of a monovoltine water strider, Gerris gracilicornis (Heteroptera: Gerromorpha). Acta Soc. Zool. Boh. 65: 181-187.

Harada T., Inoue T., Ono I., Kawamura N., Kishi M., Doi K., Inoue S. \& Hodkova M. 2000: Endocrine, ecophysiological and ecological aspects of seasonal adaptations in a water 
strider, Aquarius paludum (A minireview). Entomol. Sci. 3: $157-165$.

Hodek I. 1971: Termination of adult diapause in Pyrrhocoris apterus (Heteroptera: Pyrrhocoridae) in the field. Entomol. Exp. Appl. 14: 212-222.

HoDEK I. 1979: Intermittent character of adult diapause in Aelia acuminata (Heteroptera). J. Insect Physiol. 25: 867-871.

HoDEK I. 1983: Role of environmental factors and endogenous mechanisms in the seasonality of reproduction in insects diapausing as adults. In Brown V.K. \& Hodek. I. (eds): Diapause and Life Cycle Strategies in Insects. Junk, The Hague, pp. 9-33.

Hodek I. \& Hodkova M. 1981: Relationship between respiratory rate and diapause intensity in adults of two Heteropteran species. Vest. Cs. Spol. Zool. 45: 27-34.
Inoue T. \& Harada T. 1997: Sensitive stages in the photoperiodic determination of wing forms and reproduction in the water strider, Aquarius paludum (Fabricius). Zool. Sci. 14: 21-27.

Precht H., Christophersen J., Hensel H. \& Larcher W. 1973: Temperature and Life. Springer, New York, 779 pp.

Slama K. 1960: Oxygen consumption during the postembryonic development of Pyrrhocoris apterus (Heterometabola: Heteroptera), and its comparison with that of holometabola. Ann. Entomol. Soc. Am. 53: 606-610.

Tauber M.J., Tauber C.A. \& Masaki S. 1986: Seasonal Adaptations of Insects. Oxford Univ. Press, New York, Oxford, 411 pp.

Received April 11, 2003; revised December 15, 2003; accepted April 26, 2004 